Supplement of The Cryosphere, 11, 2059-2073, 2017

https://doi.org/10.5194/tc-11-2059-2017-supplement

(C) Author(s) 2017. This work is distributed under

the Creative Commons Attribution 3.0 License.

(c) (1)

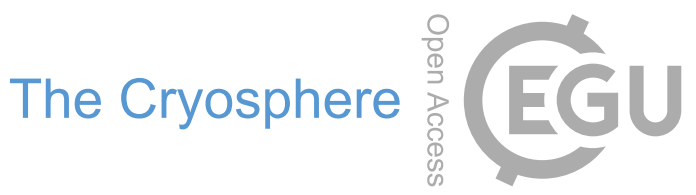

Supplement of

\title{
Comparison of CryoSat-2 and ENVISAT radar freeboard over Arctic sea ice: toward an improved Envisat freeboard retrieval
}

\section{Kevin Guerreiro et al.}

Correspondence to: Kevin Guerreiro (kevin.guerreiro@legos.obs-mip.fr)

The copyright of individual parts of the supplement might differ from the CC BY 3.0 License. 
S1: (a) Monthly freeboard difference $(\Delta f b)$ between Envisat and CryoSat-2 and (b) monthly Envisat pulse peakiness (PP) shown for the November 2011 - March 2012 period. The dark lines represent the isoline MYI fraction equal to 0.7
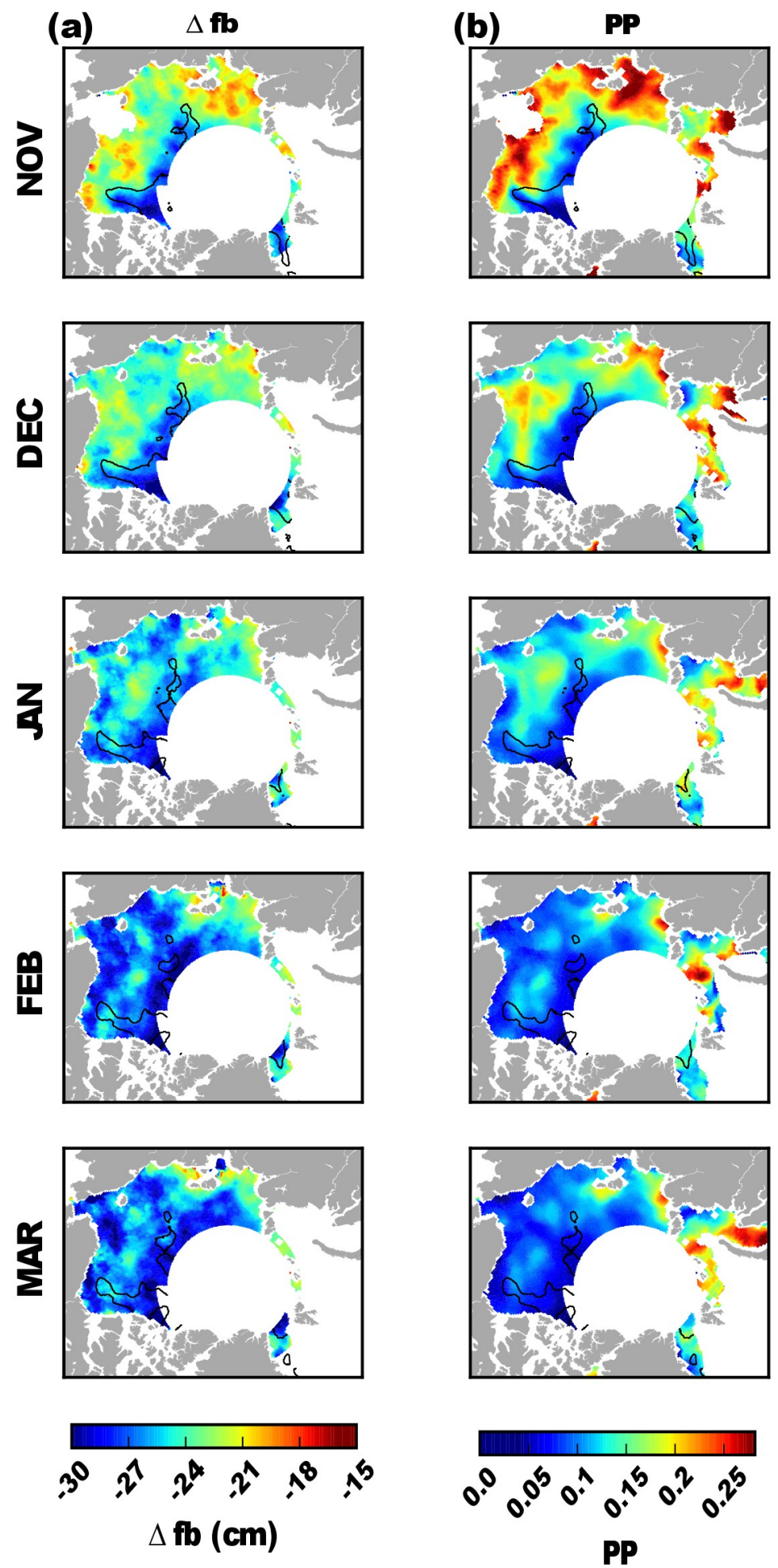
S2: (a) Envisat, (b) Envisat/PP and (c) CryoSat-2 monthly freeboard maps shown for the November 2011 - March 2012 period. The dark lines represent the isoline fraction of MYI equal to 0.7. (d) Probability Distribution Function (PDF) of Envisat (blue) and CryoSat-2 (black) radar freeboard.
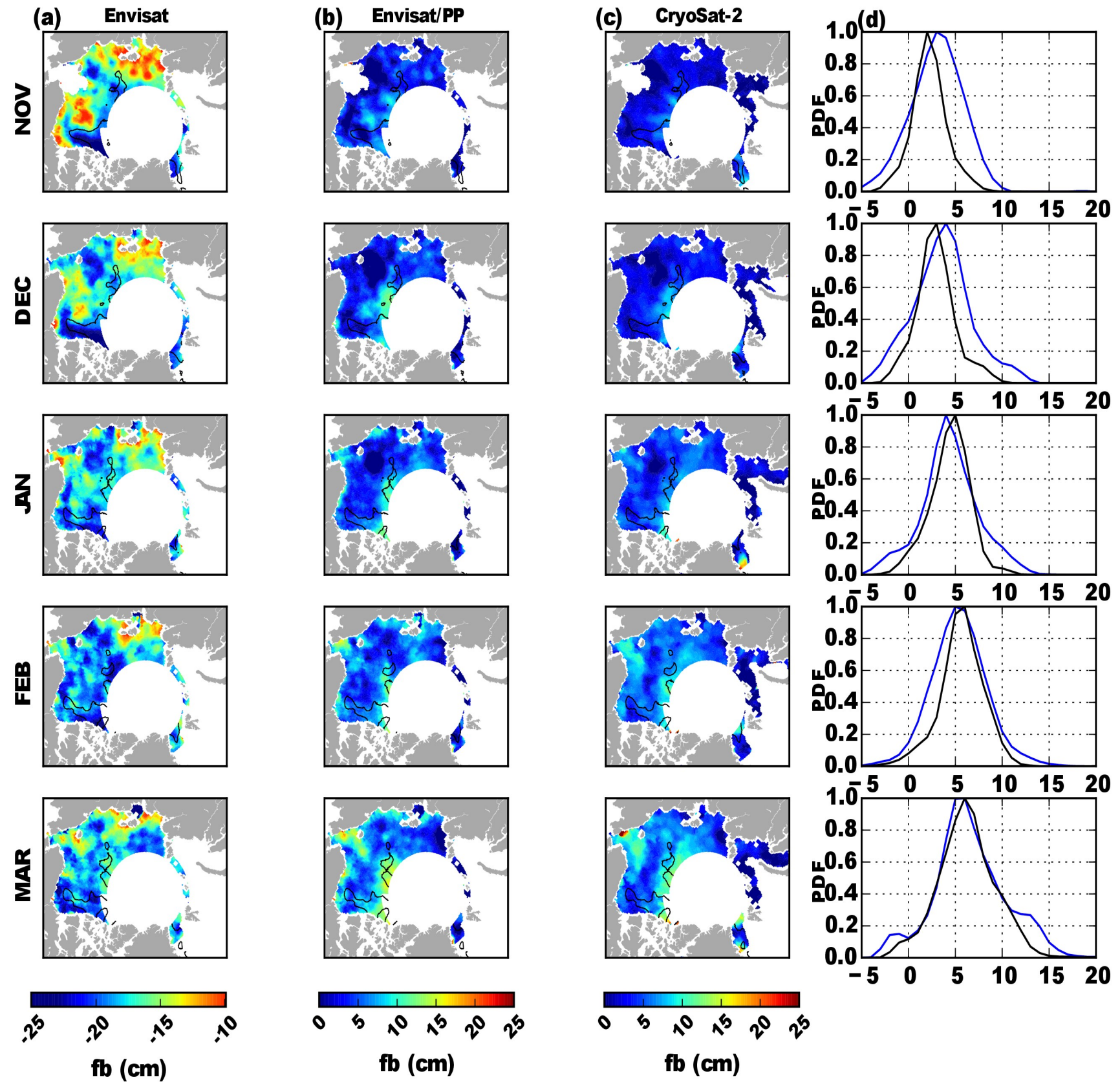